\title{
METRIC CHARACTERISTICS OF A NEW TEST FOR THE EVALUATION OF DYNAMIC BALANCE
}

\author{
Kamenka Živčić Marković', Tomislav Krističević1, and Aleksandra Aleksić-Veljković \\ ${ }^{1}$ Faculty of Kinesiology University of Zagreb, Croatia \\ ${ }^{2}$ Faculty of Sport and physical education, Novi Sad, Serbia
}

Original scientific paper

UDC: $796.412 .2: 796.012 .266$

\begin{abstract}
:
The aim of the study was to determine psychometric characteristics of a new test for the evaluation of dynamic balance in healthy individuals. The research was conducted on a sample of 60 female students (21.18 \pm 0.86 years). The participants performed three trials of the new test for each of the two different ways of walking. The results of reliability testing have showed high values of factor loadings (.91-.97) and standardized Cronbach's alpha values (.87-.98), as well as the average inter-item correlation values (full feet walking, tip toe walking and the number of steps) (.78-.94). High values of factor loadings (.88-.97) and the fact that the total explained variance was very high $(93.3 \%)$, with a relatively small variability between the attempts, suggests that all the rules for consistency of testing have been satisfied and that the new test is reliable enough for its application in practice.
\end{abstract}

Key words: balance beam, reliability, validity, artistic gymnastics

\section{Introduction}

Balance can be defined as the ability to maintain the body's centre of gravity above the base of support (Sarabon, Rosker, Loefler, \& Kern, 2010), whereby the base of support is considered as the area on the ground enclosed by the points of contact with the subject's body (Carr, 2004; Panjan \& Sarabon, 2010). In everyday life, as well as in sports, besides the ability of keeping the body in a stable position at rest, balance is commonly referred to as the ability to keep the body in a stable position during movement. Thus, in practice, we differentiate two different types of mechanical balance: a static and dynamic one. Therefore, the primary definition is generally applicable only to one of the known forms, thus ignoring the other configuration, i.e. the dynamic balance. However, dynamic balance assessment is important both in sport-specific and in everyday situations, so that consequently a number of tests for the evaluation of dynamic balance may be applied (Ricotti, 2011). The human body uses different strategies for maintaining bodily balance, and the most common refer to ankle and hip (Winter, 1995; Winter, Patla, Prince, Ishac, \& Gielo-Perczak, 1998). The first strategy compensates for the rotation and other minor disturbances, specifically in establishing and/or maintaining the stabile position, while the other is used when the supporting surface moves thus producing interferences which directly affect the loss of balance (Panjan \& Sarabon, 2010). Both strategies are very important when it comes to dynamic balance.

According to Carr (2004), balance includes both coordination and control which are essential in everyday life, and in sports as well. Coordination and control should be understood not only as the abilities to maintain a bodily position, but primarily as the abilities that enable quick restoration of the balance position after it has been disrupted in the state of either a standstill or motion. Balance can also be defined as the ability to keep one's body in a balance position and to correct the action of gravity, which makes it difficult to maintain the balance position under the influence of external stimuli. Heredity of balance is found to be very high (cf. Gajić, 1985); however, it is also conditioned by external environmental factors (Popeska, JovanovaMitkovska, \& Barbareev, 2015), and it is for this reason that balance is quite complex, specific and difficult to develop. Also, tests of dynamic balance proved to be good predictors in preventing injuries of the locomotor system. Therefore it is considered that the tests with good properties and psychometric characteristics can be applied to different clinical groups (Sarabon, Zacirkovnik, Rosker, \& Loefler, 2013).

There exists a great number of objective and subjective methods for determining the level of 
balance and postural stability (in everyday mobility, work and exercise/sports activities). Some of them are: Romberg test, Chattecx Balance System, EquiTest system, Biodex Stability System, Balance Error Scoring System (BESS), Star Excursion Balance Test (SEBT), and Y balance test (Arnold \& Schmitz, 1998; Susco, Valovich McLeod, Gansneder, \& Shultz, 2004; Demura \& Yamada, 2010). Advancements in technology have enabled scientists to perform the quantitative testing of balance by tensiometric platforms. Balance platform testing was developed for the purpose of applied studies of locomotion, especially for biomechanical gait analysis, and for the treatment of movement disorders caused by an illness or injury. Balance platforms have also found their place in the training of skilled movements in different sports (Whiting \& Zernicke, 2008). Such systems are easy, convenient and efficient methods of testing, but often very expensive. When used widely in healthy individuals, testing procedures conducted by measuring instruments that do not require expensive equipment and long periods of time are necessary.

Reliability of tests is checked by repeated measurements and a large number of repetitions, and it is characterized by a low variability between subjects and a high correlation between repeated testing (Marina \& Torrado, 2013). Accurate, reliable tests enable quality monitoring of subjects' capabilities, so that these tests must be adapted to age, gender and abilities of subjects. This is particularly important when considering the relationship between dynamic balance and risk factors that might lead to injuries to the locomotor system. Reliability, validity, sensitivity and objectivity are psychometric characteristics of tests (Sarabon et al., 2013) which can serve for the selection and application of appropriate tests in practice.

The aim of this study was to determine some psychometric characteristics of a new test which is intended for the evaluation of dynamic balance. The study was conducted on a population of healthy, physically active females who were included in the training process within a basic curricular three-month artistic gymnastics programme that contained basic movements and technical elements on the balance beam. The test has been designed to determine the application of dynamic balance, and it tends to be used for the prediction of the quality of performance on the balance beam and of some movements in the physical education curriculum, but also in sports where dynamic balance has direct impact on results.

\section{Methods}

\section{Participants}

The study included 60 female students (21.18 \pm 0.86 years) who volunteered and signed a written consent to participate in the research. Before the beginning of the testing, the objectives and procedures of the research were explained to the participants. All the participants confirmed that they did not sustain any injuries to ligaments, joints or muscles in the three months prior to the testing. All procedures in the study were carried out according to the latest version of the Declaration of Helsinki (World Medical Association, 2002).

\section{Procedures}

The equipment necessary for task performance consisted of a Swedish bench, two mats, five onemetre long sticks and a stopwatch. The bench was turned upside down and its wider surface was placed on five sticks lying on the floor and perpendicular to the long axis of the bench. The sticks were distributed at equal distance between the two mats placed on either side of the bench, i.e. one end of the bench was placed on the mat from which a participant started the execution of the task, and the other end of the bench was placed 0.5 metres away from the other mat where the participant ended the task (Figure 1).

In this dynamic balance test, the participants' goal was to walk on the Swedish bench for 5 metres from one end of the bench to the other, without falling off it. Two ways of walking on the bench were mandatory: ordinary, full-feet walking (WALK) and tip toe walking with arms extended overhead (TIPTOE). The task was completed after both feet had touched the mat placed on the other end of the bench. The starting position of the participant was with one foot placed on the Swedish bench and the other foot on the end of the starting mat. When a signal was given, the participant raised a leg off the mat and performed the task. The task was completed when the participant had arrived to
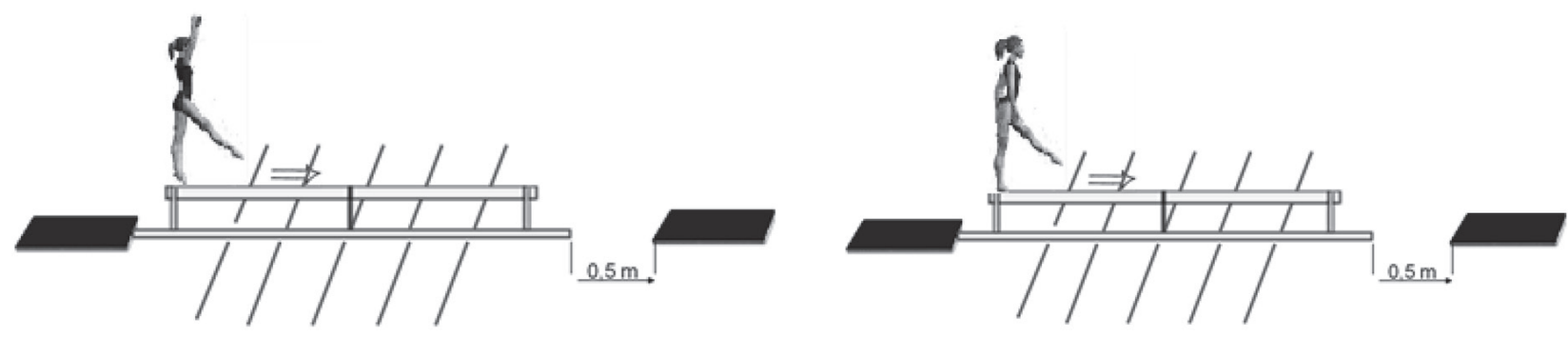

Figure 1. Test WALK, and test TIPTOE 
the other side of the bench and touched the end of the second mat with both feet. Each walking mode was performed three times, and the tester recorded the time in seconds for each of the three attempts. The number of steps (NSWALK/NSTOE) required to cover the whole length of the bench was also recorded. If a participant fell/stepped down from the bench and touched the floor with either one or both feet, the trial was considered unsuccessful and the participant had to repeat it.

\section{Statistical analysis}

Statistical analyses were conducted in SPSS 22.0 for Windows. The significance level was set at $\mathrm{p}<.05$. Descriptive statistics (mean - Mean and standard deviation - SD) was calculated for each of the three trials in the two modes of the test. Interitem correlation matrix was created for all variables. Reliability and homogeneity of testing were shown by Cronbach's alpha coefficients, standardized alpha, and average values of correlation coefficients between the items (average inter-item correlation). The factorial validity of the new test has been determined from the factor structure matrix.

\section{Results}

Table 1 shows that in WALK (full feet walking) the average value of the time required for a successful covering of the 5-metre distance ranged from 2.85 to 3.55 seconds during which 5.55-6.10 steps were performed (NSWALK). In TIPTOE (tip toe walking with arms extended overhead) the participants covered the distance in 4.17-5.02 seconds and made 6.72 to 7.20 steps (NSTOE). Standard deviation (SD) values of the three measured items in WALK ranged between 0.82 and 1.21 seconds, and the number of steps ranged between 0.92 and 1.22 in the variables NSWALK and NSTOE, whereas standard deviations for the TIPTOE variable had higher values and fell between 1.84 and 2.19.

The results of reliability testing (Table 1) showed high values of factor loadings, visible from the value of Cronbach's alpha (.91-.97) and standardized alpha values (.87-.98), as well as the average inter-item correlation values (.78-.94). The high factor loadings (.88-.97) and the fact that the total explained variance was very high (93.3\%) with little variability between the attempts, suggested that all the rules for consistency of testing were satisfied, and that the new test is reliable enough for application in practice.

The value of the ICC (inter-item correlation) (Table 2) and the average value of the ICC coefficients (Table 1) of the test were high (.77-.97), thus indicating good homogeneity of the assessment tool. Due to the fact that homogeneity, as a psychometric characteristic, plays an important role in describing an assessment tool (because it depends on the diagnostic value of a test), it can be concluded that the test applied in our research provides answers to the question why someone performs better and someone performs worse, which makes the assessment tool usable for diagnostic purposes.

Table 1. Descriptive statistics, factorial validity and predictability of dynamic balance test

\begin{tabular}{|c|c|c|c|c|c|c|c|c|}
\hline Item & Mean & SD & $\begin{array}{c}\text { Factor } \\
\text { loadings }\end{array}$ & Eigenvalue & $\%$ Total & $\begin{array}{c}\text { Cronbach's } \\
\text { alpha }\end{array}$ & $\begin{array}{c}\text { Standardized } \\
\text { alpha }\end{array}$ & $\begin{array}{c}\text { Average } \\
\text { inter-item corr. }\end{array}$ \\
\hline \multicolumn{9}{|c|}{ WALK } \\
\hline I. & 3.55 & 1.21 & .88 & 2.74 & 0.93 & .95 & .87 & .87 \\
\hline II. & 3.05 & 0.85 & .92 & & & & & \\
\hline III. & 2.85 & 0.82 & .94 & & & & & \\
\hline \multicolumn{9}{|c|}{ NSWALK } \\
\hline I. & 6.10 & 1.22 & .94 & 89.38 & 2.68 & .94 & .94 & .84 \\
\hline II. & 5.72 & 1.06 & .96 & & & & & \\
\hline III. & 5.55 & 0.96 & .97 & & & & & \\
\hline \multicolumn{9}{|c|}{ TIPTOE } \\
\hline I. & 5.02 & 2.19 & .84 & 95.65 & 2.87 & .97 & .98 & .94 \\
\hline II. & 4.39 & 1.84 & .93 & & & & & \\
\hline III. & 4.17 & 1.93 & .92 & & & & & \\
\hline \multicolumn{9}{|c|}{ NSTOE } \\
\hline I. & 7.20 & 1.07 & .95 & 85.64 & 2.57 & .91 & .92 & .78 \\
\hline II. & 6.88 & 1.01 & .97 & & & & & \\
\hline III. & 6.72 & 0.92 & .95 & & & & & \\
\hline
\end{tabular}

Note. Item - measurement; Mean - mean value; SD - standard deviation from the mean; Factor loading - correlation coefficient between the item and the principal component; Eigenvalue - total explained variance; \%Total - percentage of explained variance; Cronbach' alpha - Cronbach's reliability coefficient; Standardized alpha - standardized reliability coefficient; Average inter-item corr. - average inter-item correlation coefficient 
Table 2. Inter-item correlation

\begin{tabular}{lcc}
\hline & WALK1 & WALK2 \\
\hline WALK2 & .829 & \\
WALK3 & .866 & .916 \\
\hline & NSWALK1 & NSWALK2 \\
\hline NSWALK2 & .811 & .919 \\
NSWALK3 & .790 & TIPTOE2 \\
\hline \multicolumn{3}{c}{ TIPTOE1 } \\
TIPTOE2 & .939 & .945 \\
\hline TIPTOE3 & .921 & NSTOE2 \\
\hline NSTOE2 & NSTOE1 & .783 \\
NSTOE3 & .774 & \\
\hline
\end{tabular}

Note. WALK - full feet walking; TIPTOE - tip toe walking; NSWALK, NSTOE - number of steps

The results of factor analysis isolated two very clear latent dimensions (Table 3). The first factor was dominated by high correlations of NSTOE, WALK and NSWALK variables, and the second one by high correlations (.967-.934) of TIPTOE variables.

Table 3. Factor structure matrix of the dynamic balance test

\begin{tabular}{lcc}
\hline & Factor 1 & Factor 2 \\
\hline NSTOE1 & .835 & .274 \\
NSTOE2 & .704 & .344 \\
NSTOE3 & .704 & .448 \\
WALK1 & .674 & .549 \\
NSWALK1 & .895 & .077 \\
WALK2 & .613 & .613 \\
NSWALK2 & .935 & .134 \\
WALK3 & .596 & .603 \\
NSWALK3 & .931 & .115 \\
TIPTOE1 & .252 & .934 \\
TIPTOE2 & .154 & .967 \\
TIPTOE3 & .107 & .950 \\
\hline
\end{tabular}

Note. WALK - full feet walking; TIPTOE - tip toe walking; NSWALK, NSTOE - number of steps

The analysis of the results has revealed that sensitivity, validity and reliability of the new test for dynamic balance point to its good metric characteristics.

\section{Discussion and conclusions}

The aim of this study was to determine the reliability and validity of a new test of dynamic balance. The results indicate that the test is suitable for determining the dynamic balance abilities and that its application in practice can be recommended. The objectivity of the test is provided by the fact that it estimates the time needed to cross the length of the bench and the number of steps that a participant makes. The evaluation of the test is very simple and does not require special training of testers, thus escaping a disadvantage of many investigations, i.e. complicated testing (Panjan \& Sarabon, 2010). In some previous studies (Robertson, Collins, Elliott, \& Starkes, 1994; Robertson \& Elliot, 1996) of the ways to estimate dynamic balance a balance beam was used, but metric characteristics of those tests were not studied. Participants were gymnasts of different levels, but besides measuring the time needed to walk the whole length of the beam and counting the number of steps, the testers also counted the errors in performance (subjective meaning of gymnastic experts), which affected the objectivity of measurements.

In spite of both a large number of tests employed to assess balance and the fact that numerous authors have investigated this ability (Kinzey \& Armstrong, 1998; Ricotti, 2011; Zemková, 2011; Grible, Kelly, Refshauge, \& Hiller, 2013), there are still new possibilities of analysing that area of motor abilities, especially in some sports in which balance (especially the dynamic type of balance) is one of the dominant performance requirements. Balance is a very important motor ability in many sports (rollerblading, skating, skiing, rhythmic gymnastics, etc.), and it is of paramount relevance in artistic gymnastics, which belongs to the set of basic sports. In addition to the significance of balance for quality performance in sport, this ability is present and important in everyday life. We should keep in mind that balance is certainly linked with other motor abilities, specifically strength and coordination, as well as flexibility, which is often neglected in spite of its significance in injury prevention (Hrysomallis, 2007; Martínez-López, Hita-Contreras, JiménezLara, Latorre-Román, \& Martínez-Amat, 2014). Coordination, strength and flexibility, and thus balance, are developed from earliest childhood through basic forms of movement such as sitting, crawling and walking. For this purpose, one of the most frequently used batteries of tests applied in practice is the Bruininks-Oseretsky Test of Motor Proficiency (BOTMP) (Deitz, Kartin, \& Kopp, 2007; Cushing, Chia, James, Papsin, \& Gordon, 2008). This test is used by educators and therapists for diagnostic testing of children, usually children with special needs. It contains 46 tasks divided into eight subgroups, one of which is balance (nine tests). One of the tasks used for the evaluation of dynamic balance is walking along a line (marked on the ground), so that the heel of the front leg touches the toes of the other leg.

It must be noted that considering the whole range of sports, dynamic balance is evidently closely associated with and predominant in artistic gymnastics (Bressel, Yonker, Kras, \& Heath, 2007; 
Hedbávný, et al., 2013). Being a basic sport, the contents of gymnastics are applicable to different purposes: recreation, education, medical treatment, and in different sports to develop basic motor skills and physical condition of athletes. For this reason, the question is how to define balance easily and precisely, and accordingly, how to connect it with a specific sports activity (Atilgan, 2013; Bressel, et al., 2007: Fotios, et al., 2013; Hrysomallis, 2011; Zemková, 2014).

During execution of elements on a beam in which an athlete moves along a narrow surface, initial direction of motion is critical. Movement must be accurately matched to the surface of the beam. Otherwise participants may lose the balance position, and consequently stability (Carr, 2004). For this reason, attention must be paid to the starting position and the beginning of the performance of each technical element and all subsequent movements to be performed. Stabilization of initial body position, initial body movement and early correction of motion direction are also of great importance (Winter, 1995). Along with the starting position of initial stepping on a narrow surface, importance of the movement of the apparatus during the execution of the test was also taken into account, so that the sticks were placed in such a way as to move forward in the same direction as the participant. This also made the task performance difficult, since it forced the participants to put additional effort into maintaining and achieving balance (Ricotti, 2011).

Similarly, in the second version which is not related to ordinary walk, the task was made more difficult by standing on tip toes, which directly reduced the support area, and extending arms upwards. The upward position of arms prevented any possible arm movements that a gymnast could make in an attempt to keep the balance (Milosevic, McConville, \& Masani, 2011). There are two basic situations in which balance on a balance beam is usually lost: forward - back, when balance is easily established by stepping forward or back, and balance loss in the lateral direction, when the renewed balance position requires additional movement of head, hands, shoulders and body, or a free leg. By positioning the athletes' body in this way, we have tried to complicate the task, and bring it closer to the situational characteristics of movement and exercise on the balance beam (Atkeson \& Stephens, 2008; Ricotti, 2011). The participants performed the task barefoot, which additionally emphasized the role of the vestibular system due to its functional stability (orientation ability and balance maintenance), of movement analyzers (which help a gymnast to control muscles easily and quickly, thus obtaining a good representation of her movement), as well as of the importance of tactile analyzers which help to record the pressure when leaning against an apparatus or when touching an apparatus on which a movement is executed (Guskiewicz, 2011).

The results of factor analysis, which showed a clear distinction between two latent factors, indicated that TIPTOE (walking on tiptoes with arms up) contained additional dimensions that were not immediately identified. The reasons for this are multi-faceted. The implementation of this test requires knowledge of techniques, its situational use and good body posture. The responding posture during the change of position is estimated by dynamic balance tests (Bouisset \& Do, 2008; Lugade, Lin, \& Chou, 2011), so we can assume that regardless of the separation into two factors, compared to other subtests carried out, this test still has its significance in the measurement of dynamic balance. Balance, as well as fine motor skills, is frequently incorporated in coordination (Ricotti, 2011), together with a sense of rhythm and spatial orientation. It is well known that in the hierarchy of motor abilities a mechanism that is the most responsible for balance is the mechanism for synergistic control and regulation of muscle tonus, as one of the subsystems of the movement regulation mechanism (Ricotti, 2011). The mechanism for synergistic control and regulation of muscle tonus allows the execution of motor tasks on different levels of complexity, and it is also responsible both for flexibility in individual topological regions of the body and for speed of simple movements. It can be assumed that the variable TIPTOE incorporated more abilities that are also responsible for the successful maintenance of the balance position. Flexibility of the ankle joint and toes, speed of simple movements and the operation of the mechanism for movement structuring are directly responsible for frequency of movements and coordination in space.

No motor ability, especially in sport and sportspecific techniques, can be regarded in isolation, so further research should verify the relationship between the proposed dynamic balance test and the remaining basic motor abilities, as well as the whole body muscle strength that defines posture. This refers mainly to proper upright posture, joint flexibility (especially the ankle, knee and hip joints) and basic coordination abilities related to spatial orientation and harmonious operation of different parts of the body, i.e. their timing.

Very high values of validity, reliability and homogeneity of all measured parameters of both versions of the test have shown that this test is, compared to currently known things about the way of measuring balance, very close to the situational characteristics of movement along the balance beam (Sipp, Gwin, Makeig, \& Ferris, 2013). This characteristic is related to the basic features and characteristics of maintaining and establishing a balance position on the balance beam, especially when 
performing a specific task. It can also be assumed that this test can be applied in numerous aspects of physical activity, both in a selected physically active and in a non-selected population.

In terms of equipment and spatial conditions, it is possible to apply the test both indoors and outdoors. The test was primarily examined for its application in education with an objective to connect it with performance, i.e. performance quality of individual sport-specific elements, especially in artistic gymnastics' technical elements characteristic for balance beam.

\section{References}

Arnold, B.L., \& Schmitz, R.J. (1998). Examination of balance measures produced by the Biodex stability system. Journal of Athletic Training, 33(4), 323-327.

Atilgan, O.E. (2013). Effects of trampoline training on jump, leg strength, static and dynamic balance of boys. Science of Gymnastics Journal, 5(2), 15-25.

Atkeson, C.G., \& Stephens, B. (2008). Multiple balance strategies from one optimization criterion. Proceedings of the 7th IEEE-RAS International Conference on Humanoid Robots, HUMANOIDS 2007 (pp. 57-64).

Bouisset, S., \& Do, M.C. (2008). Posture, dynamic stability, and voluntary movement. Neurophysiologie Clinique, 38(6), 345-362.

Bressel, E., Yonker, J.C., Kras, J., \& Heath, E.M. (2007). Comparison of static and dynamic balance in female collegiate soccer, basketball, and gymnastics athletes. Journal of Athletic Training, 42(1), 42-46.

Carr, G. (2004). Sport mechanics for coaches. Champaign, IL: Human Kinetics.

Cushing, S.L., Chia, R., James, A.L., Papsin, B.C., \& Gordon, K.A. (2008). A test of static and dynamic balance function in children with cochlear implants: The vestibular Olympics. Archives of Otolaryngology, Head \& Neck Surgery, 134(1), 34-38.

Deitz, J.C., Cartin, D., \& Kopp, K. (2007). Review of the Bruininks-Oseretsky Test of Motor Proficiency, Second Edition (BOT-2). Physical \& Occupational Therapy in Pediatrics, 27(4), 87-102.

Demura, S., \& Yamada, T. (2010). Proposal for a practical star excursion balance test using three trials with four directions. Sports Sciences for Health, 6(1), 1-8.

Fotios, M., Miltiadis, P., Eirini, A., \& Andromahi, S. (2013). Dynamic balance in girls practicing recreational rhythmic gymnastics and Greek traditional dances. Science of Gymnastics Journal, 5(1), 61-70.

Gajić, M. (1985). Osnovi motorike čoveka. [Bases of human movement. In Serbian.] Novi Sad: OOUR Institut fizičke kulture.

Gribble, P.A., Kelly, S.E., Refshauge, K.M., \& Hiller, C.E. (2013). Inter-rater reliability of the Star Excursion Balance Test. Journal of Athletic Training, 48(5), 621-626.

Guskiewicz, K.M. (2011). Balance assessment in the management of sport-related concussion. Clinics in Sports Medicine, 30(1), 89-102.

Hedbávný, P., Sklenaříková, J., Hupka, D., \& Kalichová, M. (2013). Balancing in handstand on the floor. Science Of Gymnastics Journal, 5(3), 69-80.

Hrysomallis, C. (2007). Relationship between balance ability, training and sports injury risk. Sports Medicine, 37(6), $547-556$.

Hrysomallis, C. (2011). Balance ability and athletic performance. Sports Medicine, 41(3), 221-232.

Kinzey, S.J., \& Armstrong, C.W. (1998). The reliability of the star-excursion test in assessing dynamic balance. The Journal of Orthopedic and Sports Physical Therapy, 27(5), 356-360.

Lugade, V., Lin, V., \& Chou, L.S. (2011). Center of mass and base of support interaction during gait. Gait and Posture, 33(3), 406-411.

Marina, M., \& Torrado, P. (2013). Does gymnastics practice improve vertical jump reliability from the age of 8 to 10 years? Journal of Sports Sciences, 31(11), 1177-1186.

Martínez-López, E.J., Hita-Contreras, F., Jiménez-Lara, P.M., Latorre-Román, P., \& Martínez-Amat, A. (2014). The association of flexibility, balance, and lumbar strength with balance ability: Risk of falls in older adults. Journal of Sports Science and Medicine, 13(2), 349-357.

Milosevic, M., McConville, K.M.V., \& Masani, K. (2011). Arm movement improves performance in clinical balance and mobility tests. Gait and Posture, 33(3), 507-509.

Panjan, A., \& Sarabon, N. (2010). Review of methods for the evaluation of human body balance. Sport Science Review, 19(5), 131-163.

Popeska, B., Lovanova-Mitkovska, S., \& Barbareev, K. (2015). Manifestation, measurement and assessment of balance in 7 year old children. Research in Kinesiology, 43(1), 115-121.

Ricotti, L. (2011). Balance monitoring in young athletes. Journal of Human Sport \& Exercise, 6(4), 616-628. 
Robertson, S., Collins, J., Elliott, D., \& Starkes, J. (1994). The influence of skill and intermittent vision on dynamic balance. Journal of Motor Behavior, 26(4), 333-339.

Robertson, S., \& Elliott, D. (1996). The influence of skill in gymnastics and vision on dynamic balance. International Journal of Sport Psychology, 27(4), 361-368.

Sarabon, N., Rosker, J., Loefler, S., \& Kern, H. (2010). Sensitivity of body sways parameters during quiet standing to manipulation of support surface size. Journal of Sports Science and Medicine, 9(3), 431-438.

Sarabon, N., Zacirkovnik, T., Rosker, J., \& Loefler, S. (2013). Metric characteristics of the tests for dynamic balance evaluation. Physikalische Medizin Rehabilitationsmedizin Kurortmedizin, 23(3), 135-146.

Sipp, A.R., Gwin, J.T., Makeig, S., \& Ferris, D.P. (2013). Loss of balance during balance beam walking elicits a multifocal theta band electro cortical response. Journal of Neurophysiology, 110(9), 2050-2060.

Susco, T.W., Valovich McLeod, T.C., Gansneder, B.M., \& Shultz, S.J. (2004). Balance recovers within 20 minutes after exertion as measured by the balance error scoring system. Journal of Athletic Training, 39(3), 241-246.

Whiting, W.C., \& Zernicke, R.F. (2008). Biomechanics of musculoskeletal injury. Champaign IL: Human Kinetics.

Winter, D. (1995). Human balance and posture control during standing and walking. Gait and Posture, 3(4), $193-214$.

Winter, D.A., Patla, A.E., Prince, F., Ishac, M., \& Gielo-Perczak, K. (1998). Stiffness control of balance in quiet standing. Journal of Neurophysiology, 80(3), 1211-1221.

World Medical Association. (2002). World Medical Association Declaration of Helsinki: Ethical Principles for Medical Research Involving Human Subjects. Retrieved from http://www.fda.gov/ohrms/dockets/dockets/06d0331/06D0331-EC20-Attach-1.pdf on 1 1t May, 2013.

Zemková, E. (2011). Assessment of balance in sport: Science and reality. Serbian Journal of Sports Sciences, 5(4), $127-39$.

Zemková, E. (2014). Sport-specific balance. Sports Medicine, 44(5), 579-590.

Submitted: February 27, 2015

Accepted: September 21, 2016

Correspondence to:

Prof. Kamenka Živčić Marković, Ph.D.

Faculty of Kinesiology, University of Zagreb

Horvaćanski zavoj 15, 10000 Zagreb, Croatia

Phone: +385 13658775

Fax: +38513634146

E-mail: kamenka.zivcic@kif.hr 